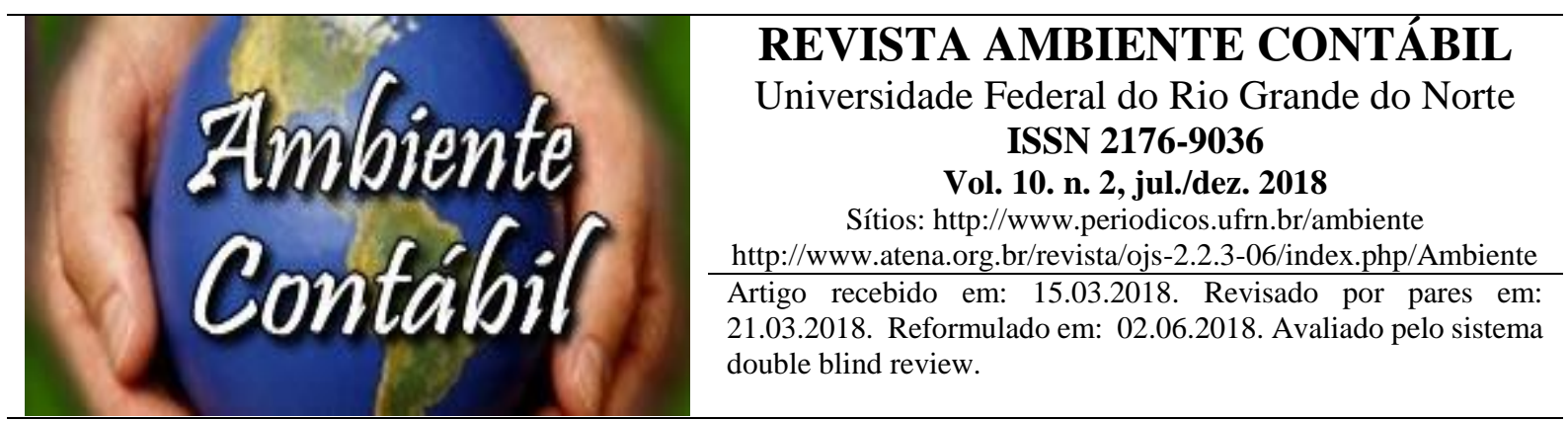

\title{
RENTABILIDADE DE CLIENTES E GESTÃO EM HOTÉIS: UM ESTUDO EM PERNAMBUCO
}

\section{CUSTOMER PROFITABILITY AND MANAGEMENT IN HOTELS: A STUDY IN PERNAMBUCO}

\section{RENTABILIDAD DE CLIENTES Y GESTIÓN EN HOTELES: UN ESTUDIO EN PERNAMBUCO}

Autoras:

Sara Beatriz da Silva Luna

Bacharelanda em Administração pela Universidade Federal Rural de Pernambuco. Endereço: Rua Dom Manuel de Medeiros, s/n, Dois Irmãos - CEP: 52171-900 - Recife/PE - Brasil.

Telefone: (81) 99646-2991 Identificadores (ID): Lattes: http://lattes.cnpq.br/3351615810756072 E-mail: sarab_luna@hotmail.com

Carla Renata Silva Leitão Doutora em Administração. Professora Adjunta da Universidade Federal Rural de Pernambuco. Departamento de Administração. Endereço: Rua Dom Manuel de Medeiros, s/n, Dois Irmãos - CEP: 52171-900 - Recife/PE - Brasil. Telefone: (81) 99920-4272 Identificadores (ID): Lattes: http://lattes.cnpq.br/0115553423642278 Research Gate: https://www.researchgate.net/profile/Carla_Leitao2 UFRPE: http://www.ppgc.ufrpe.br/?q=pt-br/docentes/carla-renata-silva-leitao E-mail: carlaleitao_ufrpe@yahoo.com.br

[Fast Track do CONCICAT - Congresso de Ciências Contábeis e Atuariais da UFPB, 2017]

\section{RESUMO}

A pesquisa teve como objetivo investigar a prática da análise da rentabilidade de clientes nos hotéis pernambucanos. A pesquisa se caracteriza como descritiva e usa como método de abordagem o estatístico. Como técnicas, utilizou a documentação direta e indireta. $\mathrm{Na}$ documentação indireta, utilizou a pesquisa bibliográfica; a documentação direta envolveu a observação direta extensiva, realizada através da aplicação de questionário. O universo da pesquisa foi composto pelos 113 hotéis pernambucanos cadastrados no Sistema de Cadastro de Pessoas Físicas e Jurídicas que Atuam no Setor do Turismo (CADASTUR), do Ministério do 
Turismo. A amostra foi composta pelos 22 hotéis que responderam ao questionário enviado. Como resultado, observou que a maioria dos hotéis, embora considere importante, não realiza a análise da rentabilidade de clientes e que a maioria, embora possua um banco de dados de clientes, não tem as informações sobre a rentabilidade contemplada em seu sistema informacional. Assim, a pesquisa buscou contribuir com o estudo do uso das informações sobre a rentabilidade de clientes na gestão dos hotéis, bem como da utilização da sua análise por essas entidades, o que pode contribuir para o estudo sobre as práticas da gestão hoteleira.

Palavras-chave: Rentabilidade de Clientes. Gestão. Hotéis.

\begin{abstract}
The objective of the research is to investigate the practice of customer profitability analysis in hotels of Pernambuco. The research is descriptive and use the statistical method. About the techniques it was used direct and indirect documentation. The indirect documentation involved a bibliographic research and direct documentation involved a questionnaire that was applied in hotels. The universe the research was 113 hotels of Pernambuco listed on Register System of Persons and Companies of the Tourism Sector (CADASTUR), of Ministry of Tourism of Brazil. The sample was composed of 22 hotels that answered the questionnaire. The results show that the most of hotels do not analyze the customer profitability, but they consider it important and although the most of hotels have a database of customers it do not have a information system that is able to provide information about the customer profitability. Thus, this research can contribute to the study of the information about customer profitability in the hotels management and its analysis, thereby contributing to studies about management practice in the hotel industry.
\end{abstract}

Keywords: Customer Profitability. Management. Hotels.

\title{
RESUMÉN
}

El objetivo de la encuesta fue el de investigar las prácticas de análisis de la rentabilidad de clientes en hoteles de Pernambuco. La encuesta es caracterizada como descriptiva y utilizo la análisis estadística. Como técnicas, utilizo la documentación directa y indirecta. En la documentación indirecta utiliza la investigación bibliográfica y en la documentación directa utiliza la observación directa extensiva, mediante un cuestionario. El universo de la encuesta fue formado por 113 hoteles de Pernambuco catastrados en el Sistema de Cadastro de Pessoas Físicas e Jurídicas que Atuam no Setor do Turismo (CADASTUR), do Ministerio de Turismo. La muestra fue integrada por 22 hoteles que respondieran el cuestionario. Los resultados muestran que la mayoria de los hoteles que integran la muestra no analizan el resultado que es obtenido con los clientes, pero considera importante y aunque la mayoria tenga um banco de datos (individual o por tipo de cliente), no tiene la información de la rentabilidad de clientes contemplada en su sistema informacional. Asi, la encuesta contribuye con el estudio del uso de la información de la rentabilidad de clientes en la gestión de hoteles y da utilización de su análisis, contribuyendo para el estudio de las prácticas de la gestión hotelera.

Palabras clave: Rentabilidad de Clientes. Gestión. Hoteles.

\section{INTRODUÇÃO}

Com o mercado em constante mudança e cada vez mais competitivo, cabe às organizações estarem sempre buscando o aprimoramento da sua gestão. Esse aprimoramento pode vir tanto através da incorporação de ferramentas e conceitos gerenciais quanto pelo uso 
de informações que possam melhorar a tomada de decisão. Dentre essas últimas, podemos destacar a informação relativa à rentabilidade do cliente.

A percepção da função vital que o cliente exerce nas organizações tem contribuído para a crescente discussão de metodologias voltadas para a análise dos clientes. Percebe-se um aumento do número de organizações que adotam uma gestão focada no cliente.

A preocupação com o cliente pode ser explicada também por algumas mudanças que vêm ocorrendo no ambiente empresarial como: abertura de mercados, aumento da velocidade dos avanços tecnológicos e o estabelecimento da informação como um diferencial.

Assim, as informações sobre clientes têm obtido mais espaço nas organizações. E, dentre as informações sobre clientes, têm se destacado aquelas relativas à rentabilidade. Jacobs, Johnston e Kotchetova (2001) destacam que a rentabilidade de clientes tem sido explorada por acadêmicos das áreas de marketing e contabilidade, sob diferentes perspectivas. Na área de marketing tem abordado o tema através do conceito de CRM (Customer Relationship Management), enquanto a literatura contábil tem se concentrado na mensuração dos custos e receitas relativos aos clientes. No entanto, ambas as áreas têm buscado identificar clientes rentáveis e não rentáveis.

Conhecer a rentabilidade de clientes pode levar aos gestores resultados que podem contribuir no desenho de estratégias organizacionais, bem como na adequação dos custos e níveis de serviços, além de subsidiar as decisões que implicam em fechamento de negócios com clientes. Para Jackman e Shanahan (2002), a análise da rentabilidade de clientes pode ainda contribuir para a realização de ações voltadas para o aumento do fluxo de caixa e/ou redução da vulnerabilidade e da volatilidade desses fluxos em relação aos clientes. Esses benefícios podem ser fundamentais em ambientes competitivos, como no caso do setor hoteleiro.

Mia e Patiar (2001) afirmam que os negócios no ambiente da indústria hoteleira são altamente competitivos, pois cada hotel sofre competição direta e indireta de outros hotéis, o que exige dos gerentes uma maior atenção aos clientes.

Ressalta-se que os hotéis são considerados importantes componentes da indústria do turismo, a qual, de acordo o Ministério do Turismo do Brasil, foi responsável pela injeção de US\$ 163 bilhões no país em 2017, o que foi equivalente a 7,9\% do Produto Interno Bruto (PIB) brasileiro nesse ano.

Os benefícios que podem ser obtidos pelos hotéis com a informação sobre a rentabilidade de clientes são destacados por Leitão (2002), que acredita que a mensuração da rentabilidade individual de clientes pelos hotéis pode auxiliar os gestores nas decisões de fechamento de pacotes turísticos, fornecimento de serviço diferenciado para um determinado cliente, realização de eventos promocionais e de divulgação, além de quaisquer decisões que se refiram à política e procedimentos com clientes.

Nesse contexto, o problema de pesquisa é estabelecido pela seguinte questão: a análise da rentabilidade de clientes é utilizada na gestão dos hotéis pernambucanos, sendo contemplada pelo sistema informacional deste? Dessa forma, o objetivo foi investigar a prática da análise da rentabilidade de clientes por esses hotéis. Com a resposta ao problema de pesquisa, o estudo pretende contribuir no fornecimento de dados sobre a análise da rentabilidade de clientes em hotéis, o que pode auxiliar na compreensão das práticas gerenciais adotadas pelo setor e impulsionar a realização de novas pesquisas sobre o tema.

$\mathrm{O}$ artigo encontra-se dividido em quatro partes, além desta introdução. A primeira apresenta um breve referencial teórico. A segunda consiste na descrição da metodologia utilizada para a realização do estudo. A terceira expõe os resultados obtidos na pesquisa realizada. Por último, são apresentadas as considerações finais. 


\section{REFERENCIAL TEÓRICO}

Jackman e Shanahan (2002) expõem que desde a década de 50 Drucker já afirmava que o cliente era a única razão para uma companhia existir, pois acreditava que para a companhia reagir e responder às necessidades do cliente era necessário analisar as informações sobre estes.

As empresas descobriram no cliente uma oportunidade de alavancar resultados, fazendo com que suas ações convirjam para o mesmo. Para Atkinson (2000), isso se deve à constatação de que todas as empresas têm clientes e por isso não podem existir indefinidamente se fracassar no atendimento às necessidades deles.

No entanto, apesar de o cliente ser fundamental para a sobrevivência das empresas, os interesses financeiros da empresa e de seus clientes caminham em sentidos opostos, pois a empresa busca maximizar os lucros enquanto o cliente deseja minimizar os custos (CROSS, 1998). Por isso as empresas devem ser capazes de aumentar o valor fornecido para o cliente e ao mesmo tempo obter rentabilidade no fornecimento desse valor.

Jacobs, Johnston e Kotchetova (2001) afirmam que a rentabilidade de clientes tem sido explorada por acadêmicos através de duas perspectivas. A primeira trata da mensuração dos custos e receitas dos clientes, voltada para a mensuração do lucro. A segunda se baseia no conceito de CRM (Customer Relationship Management), utilizado principalmente pela área de marketing.

De acordo com a literatura, a importância de se conhecer os resultados das operações com os clientes é que este conhecimento pode permitir que a empresa concentre-se em clientes rentáveis e possa transformar em rentáveis aqueles clientes que não o são. Para a mensuração dessa rentabilidade torna-se necessária a obtenção de informações sobre os resultados individuais obtidos com os clientes, através do confronto entre a receita gerada pelos clientes face aos recursos consumidos pelos mesmos, o que torna necessária a existência de um sistema de informações configurado para tal.

Segundo Horngren, Foster e Datar (2000), a rentabilidade de clientes é o resultado obtido através do confronto das receitas geradas e os recursos consumidos pelos clientes. Para os autores, os clientes, por possuírem diferentes características proporcionam resultados distintos.

Para Farris, Bendle, Pfeifer e Reibstein (2007) a rentabilidade de cliente é o lucro que a empresa tem com seu atendimento ou de um grupo de clientes no decorrer de um determinado período.

Guerreiro, Merschmann e Bio (2008) estabelecem que a análise da rentabilidade de um determinado cliente é efetuada a partir da margem de contribuição ou da margem bruta dos produtos vendidos a esse cliente menos os custos para servi-lo.

Conhecer a rentabilidade de clientes traz diversos benefícios para as empresas, Kaplan e Cooper (2000), citados por Leitão (2002) apontam várias oportunidades, como:

- Proteger os atuais clientes altamente lucrativos;

- Redefinir os preços de serviço caros, com base no custo do serviço;

- Oferecer descontos, se necessário, para fechar negócios com clientes de baixo custo;

- Negociar relacionamentos proveitosos para todas as partes, que reduzam o custo do atendimento de clientes cooperativos;

- Deixar que os concorrentes conquistem clientes que tragam prejuízos constantes;

- Tentar capturar clientes altamente lucrativos dos concorrentes.

De acordo com Mulhern (1999), as empresas precisam avaliar a rentabilidade de vários grupos de clientes, para que seja possível identificar os clientes alvos, ou seja, aqueles que se encaixam no perfil de produto/serviço oferecido. Dessa forma, eles adicionariam valor à

Revista Ambiente Contábil - ISSN 2176-9036 - UFRN - Natal-RN. v. 10. n. 2, p. 326 - 341, jul./dez. 2018. 
empresa. Para o citado autor, a empresa deve fazer esforço para reter e captar novos clientes dentro do seu segmento alvo.

A análise da rentabilidade de clientes também pode ser uma oportunidade para os gestores planejarem estratégias de marketing, alocação de custos e definição de serviços aos clientes.

Para analisar a rentabilidade de clientes, é necessário mensurar a sua rentabilidade e isso, em uma abordagem de avaliação de resultado, implica mensurar custos.

Mensurar, conforme Guerreiro (1989) a significa atribuir números a eventos ou objetivos, usando determinadas regras, com objetivo de dar significado às suas propriedades. $\mathrm{O}$ autor enfatiza que a mensuração não é só necessária para poder controlar e avaliar os resultados das atividades incluídas no processo de atingir esses determinados objetivos. Assim como toda ou qualquer atividade que sirva para analisar o ambiente, seja interno ou externo das organizações, necessita de um método que atinja a necessidade demandada pela empresa. Dessa forma, é necessário que o gestor busque a melhor forma de mensuração.

Para determinar a rentabilidade de clientes, torna-se fundamental a escolha do método de custeio a ser utilizado.

Segundo Megliorini (2011), existem diferentes métodos de custeio e a opção deve ocorrer observando-se qual deles melhor se relaciona com os objetivos estabelecidos pela empresa. Entres os métodos, podemos enfatizar o custeio por absorção, variável e por atividades.

O custeio por absorção, para Lopes de Sá (1990), designa o processo de apuração de custo que se baseia em dividir ou ratear todos os elementos do custo, para que cada centro ou núcleo absorva ou receba o que lhe cabe.

Já o custeio variável, de acordo com Hastenteufle e Larentis (2014), citado por Cruz (2011), consiste no método que aloca aos produtos e serviços apenas os custos variáveis, por considerar que os custos fixos são derivados da estrutura da empresa e não dos produtos e serviços. O custeio variável permite a identificação da Margem de contribuição.

O Custeio ABC (Activity Based Costing) é o custeio baseado em atividades. Este, de acordo com Megliorini (2011), é o método de custeio que apropria os custos dos recursos consumidos em um determinado período às atividades executadas pela empresa; o custo dos produtos resulta da soma dos custos das atividades necessária para a sua fabricação. Com o uso desse método de custeio, é possível identificar as atividades que agregam e as que não agregam valor aos produtos.

Nenhum dos métodos acima citado consegue sozinho fornecer informações completas para a empresa, contudo, o gestor deve de acordo com seus objetivos definidos, analisar as informações obtidas pela aplicação dessas formas de custeio, extraindo o máximo para sua organização, podendo fazer uma associação dos diversos métodos para chegar a um resultado mais satisfatório.

Muitas empresas mensuram a rentabilidade de seus clientes baseando-se no volume de vendas (RYALS; KNOX, 2005). Porém, o volume de vendas proporcionado por um cliente não está necessariamente ligado à sua rentabilidade e tratar a rentabilidade de clientes apenas sob o enfoque de receitas, pode ser tão insuficiente quanto tratá-la apenas sob o enfoque de custos. Ching (1997) alerta para este problema afirmando que clientes com alto volume de vendas não são necessariamente altamente rentáveis, pois rentabilidade depende de se e quanto a receita líquida cobre os custos do cliente.

Para Wyner (1999), o porquê de se calcular e melhorar continuamente a mensuração da rentabilidade de clientes é que esta pode ser uma importante parte da gestão de clientes, o que pode contribuir para melhorar a performance do negócio.Ainda para o referido autor, a mensuração da rentabilidade depende da definição do cliente, estimativa das receitas e custos 
associados a cada cliente e a combinação desses elementos dentro da rentabilidade estimada para cada cliente.

Ryals e Knox (2005) afirmam que uma dificuldade frequentemente encontrada pelas empresas que desejam mensurar a rentabilidade dos clientes é o fato de que a contabilidade gerencial e os sistemas de informações tendem a refletir mais a rentabilidade do produto do que a do cliente. Os autores explicam que sendo a rentabilidade do produto conhecida, os custos diretos do produto adquirido pelo cliente pode ser determinado com razoável acurácia. Desse modo, os custos indiretos (principalmente os de vendas, marketing e administração) são então alocados à base de clientes, de forma proporcional ao total de vendas de cada cliente. No entanto, segundo os citados autores, esta abordagem assume que cada cliente usa quantidades de tempo e esforço equivalentes da empresa; quando na verdade alguns clientes demandam mais "custos de servir" do que outros. Novos clientes podem demandar mais informações sobre os produtos/serviços do que os clientes regulares, os quais geralmente são mais previsíveis e relativamente mais fáceis de servir.

Guerreiro (1999) aponta que analisar a rentabilidade dos clientes leva às empresas a saberem quem será seus clientes alvos; aqueles que oferecerão maior retorno para a empresa. Para ele, assim as empresas poderão criar estratégias para manter esses clientes fidelizados à organização.

Devido ao benefício proporcionado, a rentabilidade de cliente vem sendo objeto de estudo de alguns pesquisadores, os quais, utilizando diferentes perspectivas, buscam analisar tanto as práticas em setores específicos, como a sua relação com variáveis relacionadas aos clientes.

Quando se trata do tema rentabilidade de clientes, alguns estudos têm sido conduzidos, principalmente nas áreas de marketing e contabilidade. Dentre estes, podemos destacar os de Jackman e Shanahan (2002), Hartfeil (1996), Noone e Griffin (1999), que exploraram a mensuração e a análise da rentabilidade de clientes, tendo o último conduzido o estudo em hotéis. Mais recentemente, podemos citar os trabalhos de Raaij (2005), Dalci, Tanis e Kosan (2010) e Cokins (2015). No Brasil, podemos citar os trabalhos de Leitão (2002), Schmidt e Santos (2011), Hastenteufel, F Larentis (2015), entre outros.

Analisando a relação entre satisfação-retenção-rentabilidade, Piva, Fumagalli, Baptista e Silva (2007) fizeram um estudo dessas variáveis no setor de plano de saúde. Chegaram à conclusão de que a Satisfação e retenção exercem impacto na receita média; a retenção de clientes não sofre variação devido às variações na satisfação; e a satisfação exerce impacto na rentabilidade.

Rosa (2001) analisou o relacionamento dessas três variáveis (satisfação-retençãorentabilidade) com canais de atendimento eletrônico. A conclusão foi de que essas variáveis interagem, porém não é estabelecida uma relação de dependência significativa. A variável satisfação está inteiramente ligada aos canais de atendimento eletrônico, causando pouco impacto na formação da rentabilidade potencial e da retenção.

Guerreiro, Merschmann e Bio (2008), realizaram um estudo em indústrias com objetivo geral de investigar a utilidade das informações resultantes da mensuração dos custos das atividades de atendimento ao cliente, para a gestão de rentabilidade de clientes. Chegaram à conclusão de que em empresas que possuem uma diversidade de produtos e serviços, a informação do custo para servir é de grande relevância para a gestão da rentabilidade, pois o entendimento da composição do custo para servir, detalhado por atividade, contribui para a definição de planos específicos para melhoria da lucratividade de clientes.

Ao estudar a rentabilidade de clientes, Santana e Andrade (2011) observaram que análise da rentabilidade de clientes é vista como uma necessidade estratégica para empresas de qualquer setor, que objetive compreender, atrair e manter clientes importantes visando a manutenção e conquista de novos clientes e, consequentemente, auferindo lucros, indispensável

Revista Ambiente Contábil - ISSN 2176-9036 - UFRN - Natal-RN. v. 10. n. 2, p. 326 - 341, jul./dez. 2018. 
para continuidade dessas entidades. Para esses autores, Trata-se de um tema relevante que necessita de mais pesquisas, especialmente quanto a modelos de mensuração para os diferentes setores da economia, de forma a permitir se chegar a um valor mais próximo da realidade para que os gestores possam tomar decisões eficazes.

Finalmente, Hastenteufel e Larentis (2014) ao estudar a rentabilidade de clientes em uma empresa de médio porte que operava na produção, venda, distribuição e montagem no segmento de móveis, verificaram que ter acesso aos resultados da análise da rentabilidade de clientes induz a organização a decisões que podem melhorar sua lucratividade, além de buscar novas alternativas de gestão. Para eles, com essas informações também é possível decidir quais clientes devem ser mantidos, avaliar aqueles que não estão sendo rentáveis e assim propor negociações para reverter esse quadro ou extinguir a relação com esse cliente para que a empresa fique aberta para novas oportunidades que tragam benefícios para ela.

\section{METODOLOGIA}

A pesquisa se caracteriza como descritiva e utilizou como método de procedimento o estatístico. No que diz respeito às técnicas, a pesquisa utilizou a documentação direta e indireta. $\mathrm{Na}$ documentação indireta, utilizou-se a pesquisa bibliográfica. Como documentação direta utilizou-se a observação direta extensiva com a aplicação de questionários.

$\mathrm{O}$ universo da pesquisa foi composto pelos hotéis pernambucanos cadastrados no Sistema de Cadastro de pessoas físicas e jurídicas que atuam no setor do turismo (CADASTUR) do Ministério do Turismo. De acordo com o CADASTUR, Em 2015, o sistema contava com 113 hotéis do Estado de Pernambuco em seu cadastro.

A amostra é caracterizada como não-probabilística. Ao se escolher esse tipo de amostra, considera-se que não será possível generalizar os resultados da pesquisa realizada, em termos de população. Por outro lado, esse tipo de amostra evitou o risco de inviabilidade da pesquisa ocasionada pela falta de alcance da amostra probabilística determinada.

Assim, a amostra foi composta pelos hotéis que responderam ao questionário enviado, o que totalizou 22 hotéis pernambucanos.

O questionário foi construído a partir do instrumento que foi utilizado no trabalho de Leitão (2002), com adaptações, e possuía a seguinte estrutura composta por 10 questões: as questões 1 a 3 destinavam-se a identificar as características dos hotéis; a questão 4 procurava detectar se os gestores do hotel possuem um banco de dados com o perfil de seus clientes; a questão 5 objetivava verificar se o hotel avaliava o resultado que o cliente proporcionava; a questão 6 buscava saber se o hotel repassava ao clientes os custos relativo ao atendimento e manutenção dos mesmos; a questão 7 investigava se o hotel conseguia avaliar a análise da rentabilidade de clientes através do sistema de informação que possuía; as questões 8 e 9 buscavam identificar se os hotéis faziam a gestão de clientes e quais ferramentas e/ou conceitos que utilizava para isso; já a questão 10 procurava identificar a importância atribuída aos hotéis à existência de sistema de informações voltados para a análise da rentabilidade de clientes.

Após a coleta dos dados, procedeu-se a tabulação dos dados, com o objetivo de se obter as frequências para cada resposta.

\section{ANÁLISES DOS RESULTADOS}

A primeira questão buscava identificar o porte dos hotéis (pequeno, médio e grande porte), quando considerado o número de unidades habitacionais (UH). Sob essa perspectiva, Dall'Igna (2014) expõe que os hotéis de pequeno porte possuem até $50 \mathrm{UHs}$, os de médio porte de 51 até 100 UHs e grande porte acima de 100 UHs. 
Partindo desse critério, observou-se, conforme pode ser observado na Figura 1, que mais de $60 \%$ da pesquisa foi respondida por hotéis de pequeno porte do setor hoteleiro em Pernambuco.

\section{Figura 1 - Porte dos hotéis}

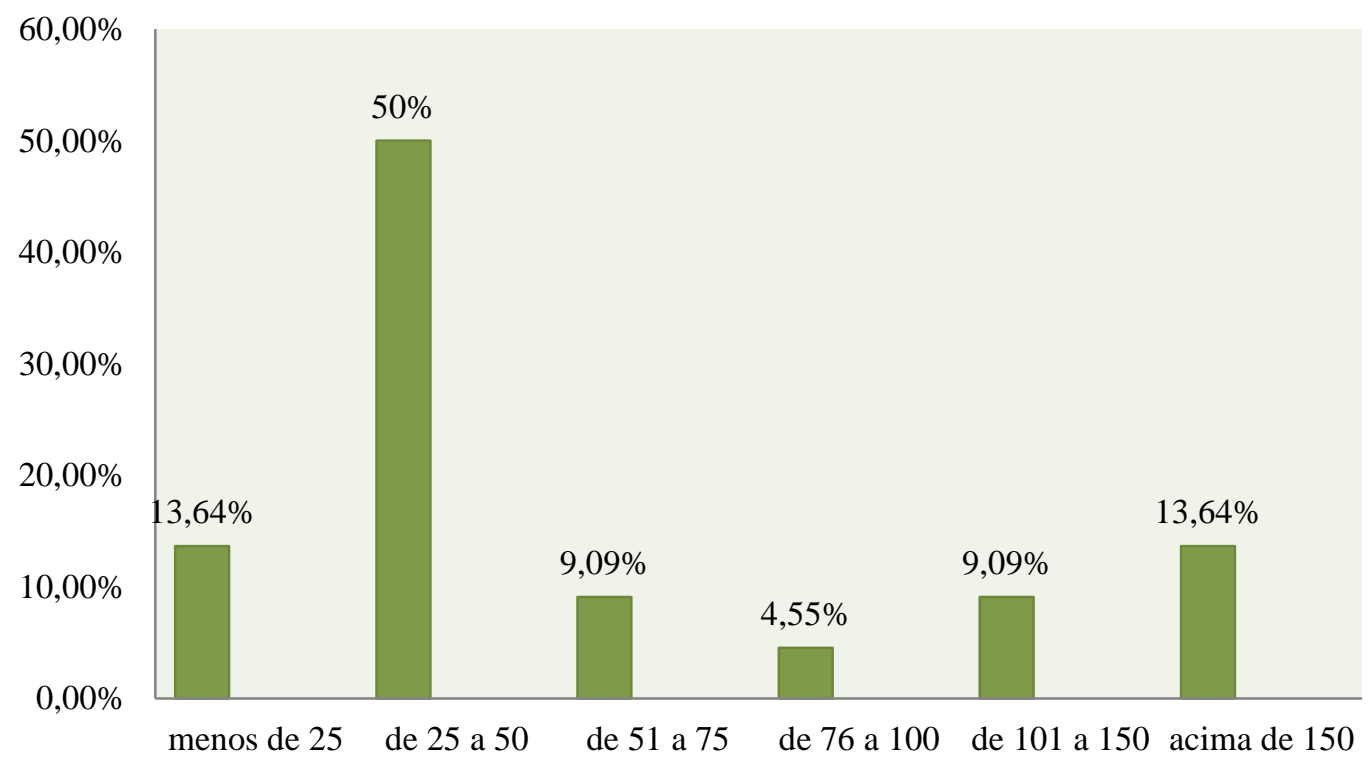

Fonte: dados da pesquisa

A segunda questão buscou identificar a propriedade dos hotéis, se eles pertenciam a uma rede nacional, internacional, se eram independentes ou se tinham sua propriedade configurada de outra forma. Observou-se, como mostra a Figura 2, que na amostra da pesquisa predominam os hotéis independentes. Esse resultado era encontra-se alinhado com os achados da questão anterior, que constatou uma predominância de hotéis de pequeno porte, cuja propriedade não costuma estar ligada a redes de hotéis. 
Figura 2 - Propriedade dos hotéis

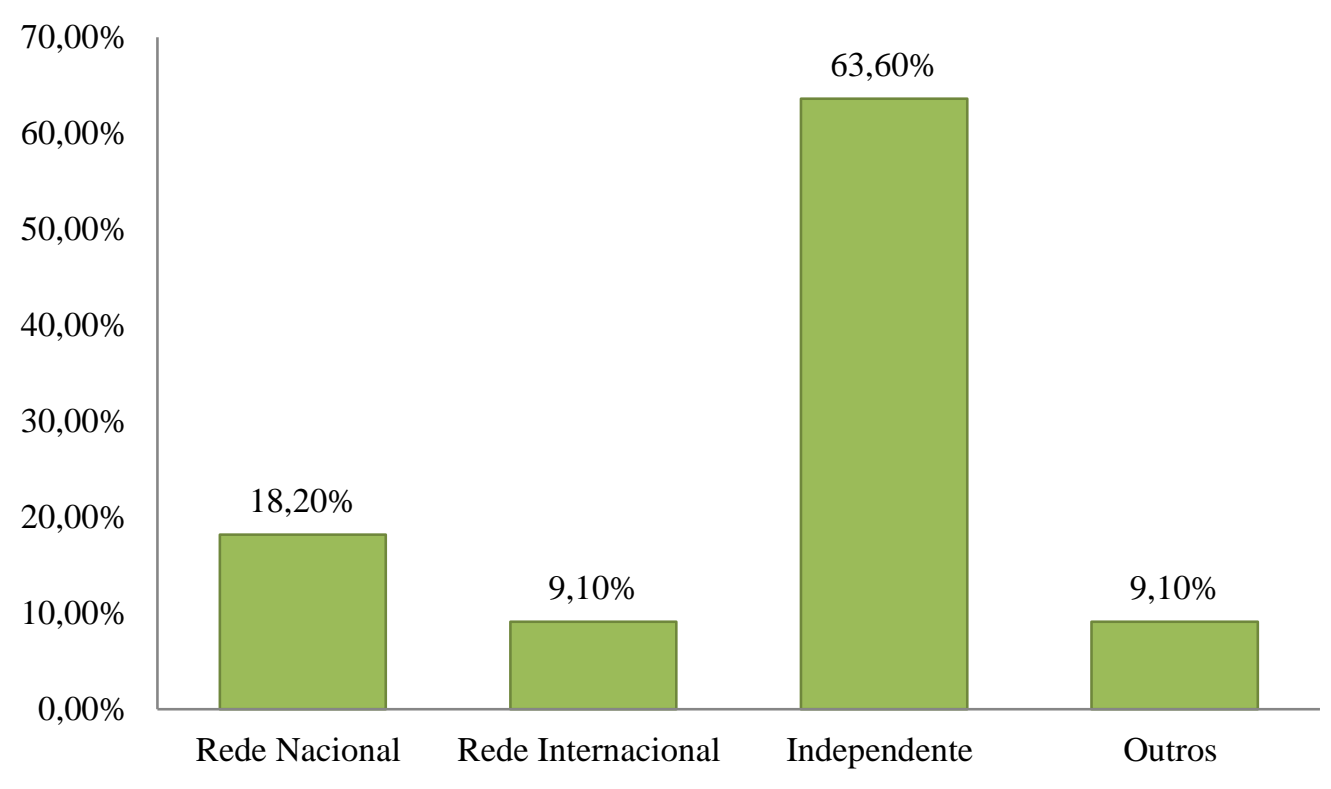

Fonte: dados da pesquisa

A questão seguinte indagava sobre a posição hierárquica de quem respondia ao questionário. Os resultados apontaram que a maioria, cerca de $32 \%$, dos questionários foram respondidos pelos gerentes gerais dos hotéis, seguido dos gerentes de área (como gerente administrativo, financeiro e de marketing). Na categoria "outros" pôde-se observar a existência de subgerente, coordenador de marketing, e alguns outros cargos. Os resultados encontram-se ilustrados através da Figura 3.

\section{Figura 3 - Posição Hierárquica dos Respondentes}

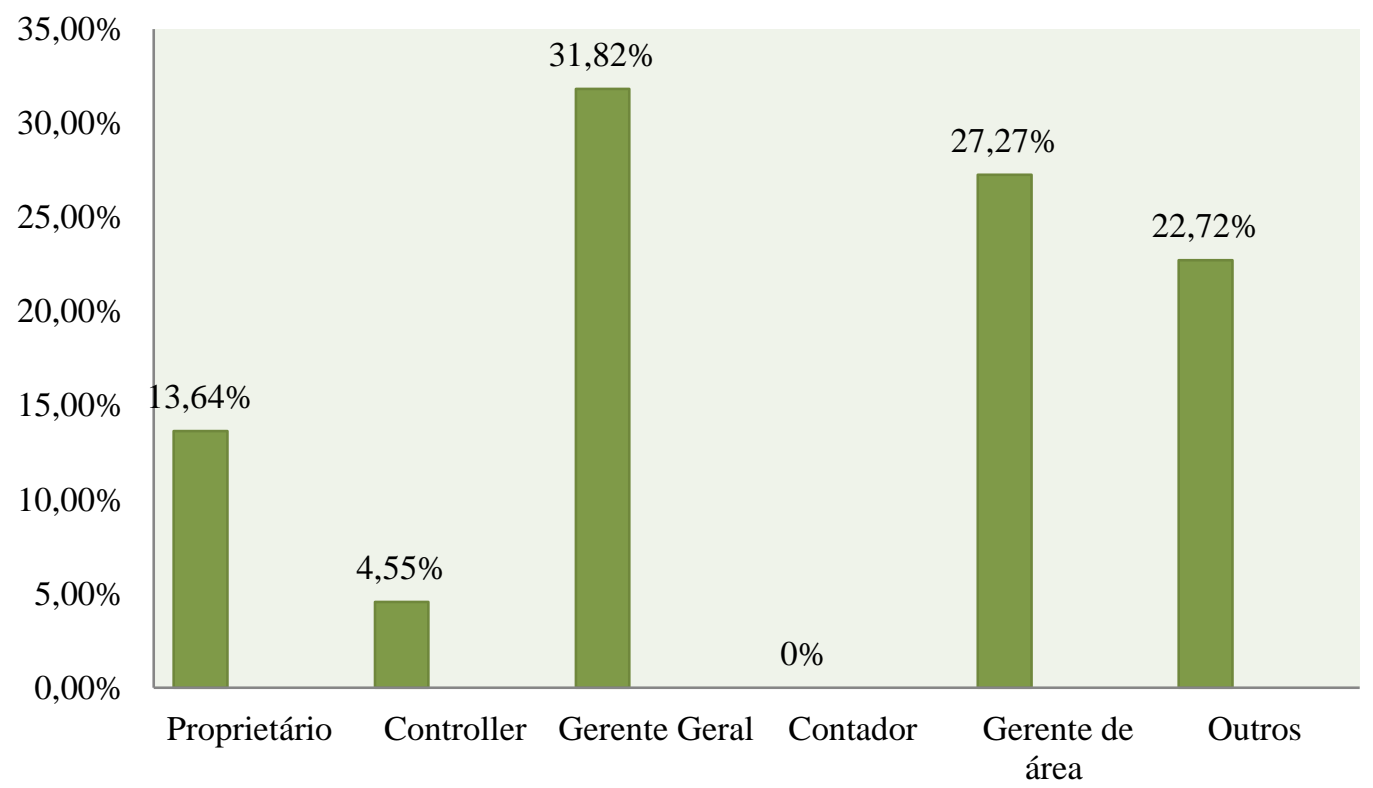

Fonte: dados da pesquisa 
Na quarta questão foi perguntado se os gestores dispunham de um banco de dados sobre o perfil de seus clientes, que servisse como suporte para uma tomada de decisão. Segundo Pereira (2001), decisões requerem informações. No caso de decisões envolvendo clientes, as informações devem ser apoiadas por um banco de dados que permita a geração de informações relativas a estes.

Quanto às respostas obtidas para a questão, observou-se que 68,20\% dos respondentes afirmaram ter um banco de dados sobre clientes, sendo que de forma mais específica $45,50 \%$ dos respondentes possuíam banco de dados individual e 22,70\% por tipo de cliente, conforme pode ser observado na Figura 4. Isso pode sinalizar que os dados sobre clientes são considerados importantes para a gestão da maioria dos hotéis. Esse resultado é diferente ao achado por Leitão (2002), que observou inexistência de banco de dados na maioria dos hotéis pesquisados, o que pode sinalizar para um aprimoramento dos bancos de dados do setor hoteleiro.

Figura 4 - Existência de Banco de Dados sobre Clientes

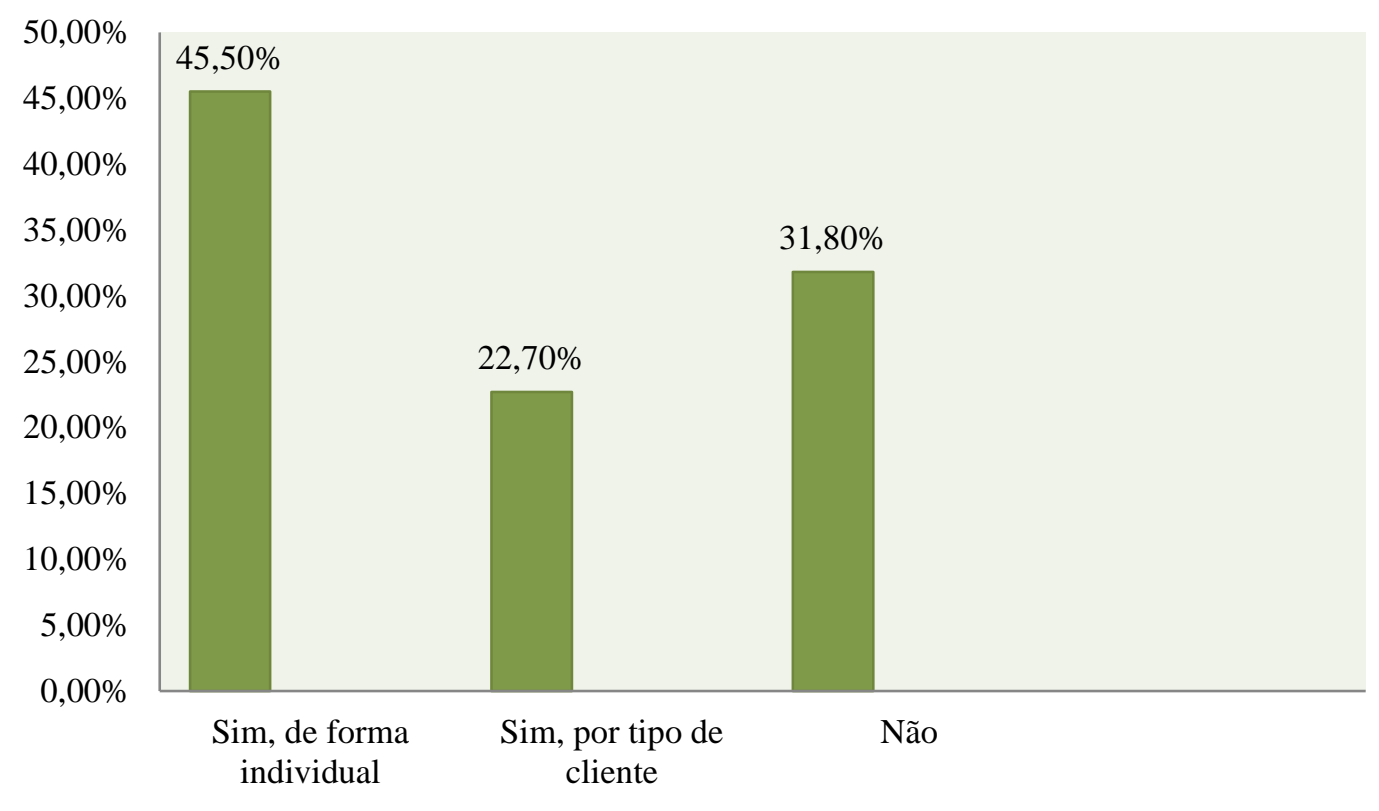

Fonte: dados da pesquisa

A questão de número cinco buscava observar se os hotéis realizavam a avaliação do resultado individual que cada cliente proporcionava. Foi percebido que mais de $70 \%$, conforme aponta a Figura 5, não avaliava os resultados que seus clientes proporcionam para seu hotel. Observou-se que $9,09 \%$ faziam a avaliação do resultado individual para todos os clientes, $13,63 \%$ o fazia apenas para alguns clientes. E ainda, que 4,55\% não avaliavam individualmente os clientes, mas apenas por tipo de cliente. Confrontado com os resultados da questão anterior, percebeu-se que embora a maioria dos hotéis afirme possuir um banco de dados de clientes, estes não demonstram utilizá-lo para avaliação do resultado proporcionado pelo cliente. A predominância da não realização da avaliação também foi observada no trabalho de Leitão (2002). 
Figura 5 - Avaliação do Resultado de Clientes

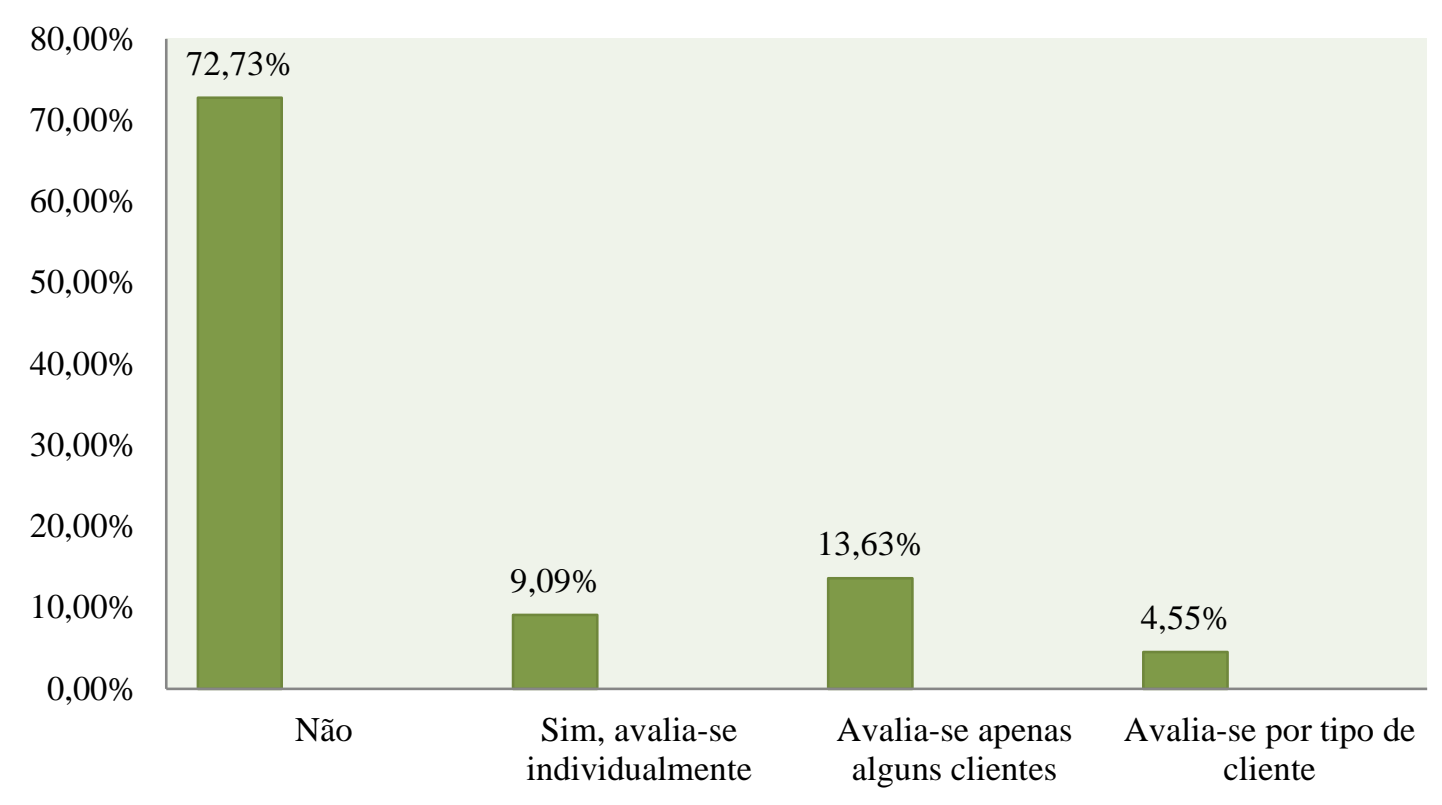

Fonte: dados da pesquisa

Quando indagados sobre se o hotel alocava aos diversos clientes os custos relativos ao atendimento e à manutenção dos mesmos, mais de 50\% afirmaram não alocar esses custos. A não alocação desses custos pode comprometer o processo de mensuração da rentabilidade dos clientes, pois conforme afirma Wyner (1999) a mensuração da rentabilidade depende dentre outras coisas dos custos associados a cada cliente. E, como aponta a Figura 6, dentre os que afirmaram realizar a alocação prevaleceu aqueles que o faziam por tipo de cliente. 
Figura 6 - Alocação dos Custos de Atendimento e Manutenção

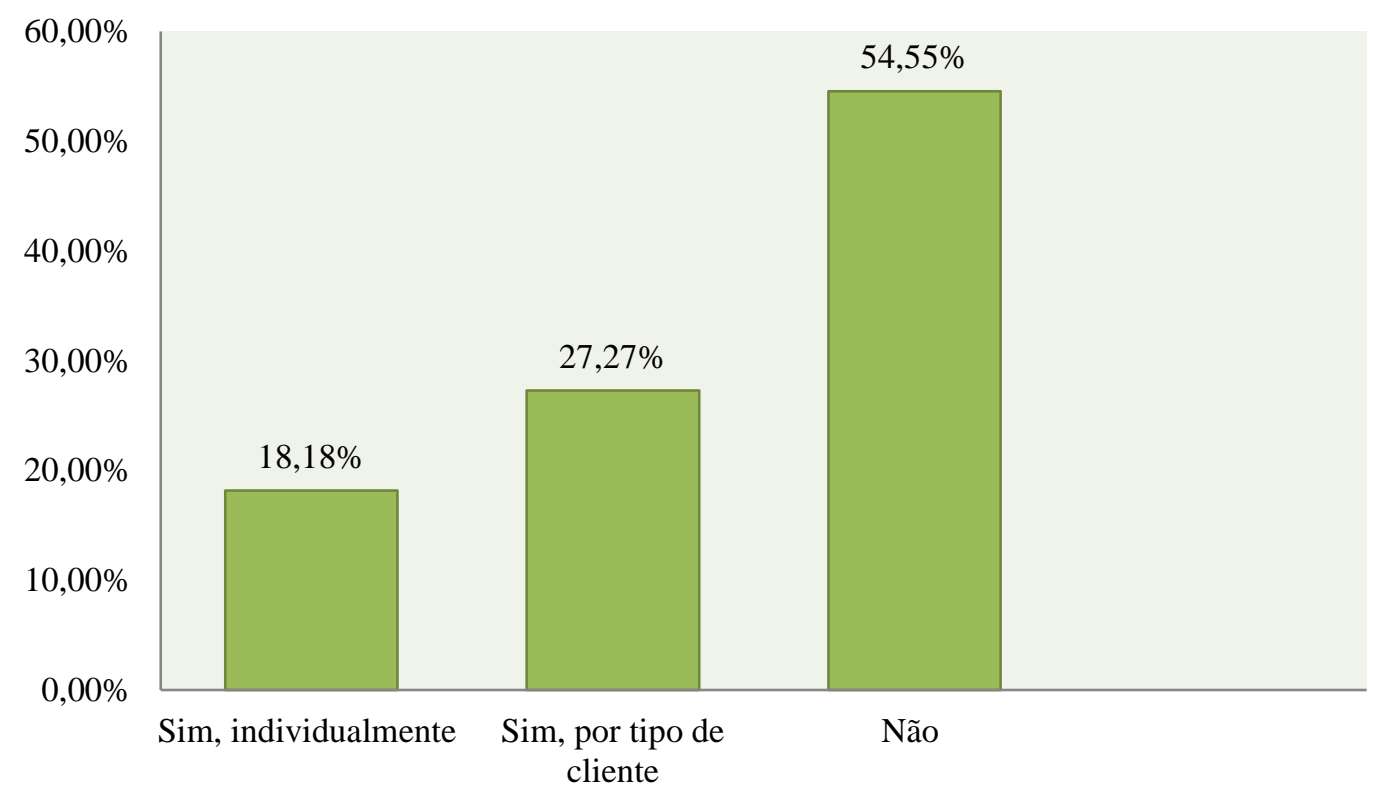

Fonte: dados da pesquisa

$\mathrm{Na}$ questão 7, ao se perguntar se o sistema de informações do hotel era capaz de proporcionar a análise da rentabilidade individual dos clientes, teve-se que $63,64 \%$ não dispunham de tal sistema. Como foi apontado no referencial teórico, analisar a rentabilidade dos clientes pode permitir à empresa informações valiosas para a gestão dos clientes e às decisões relacionadas a esse processo. No entanto, 22,73\% afirmaram possuir um sistema de informações que proporcionava a análise individual dos clientes e 13,63\% responderam que possuíam, mas por tipo de cliente. Os resultados podem ser visualizados na Figura 7.

Destaca-se que esse resultado encontra-se alinhado àquele obtido para a questão da avaliação do resultado, na qual a maioria respondeu não realizar tal prática.

Figura 7 - Existência de Sistema de Informações

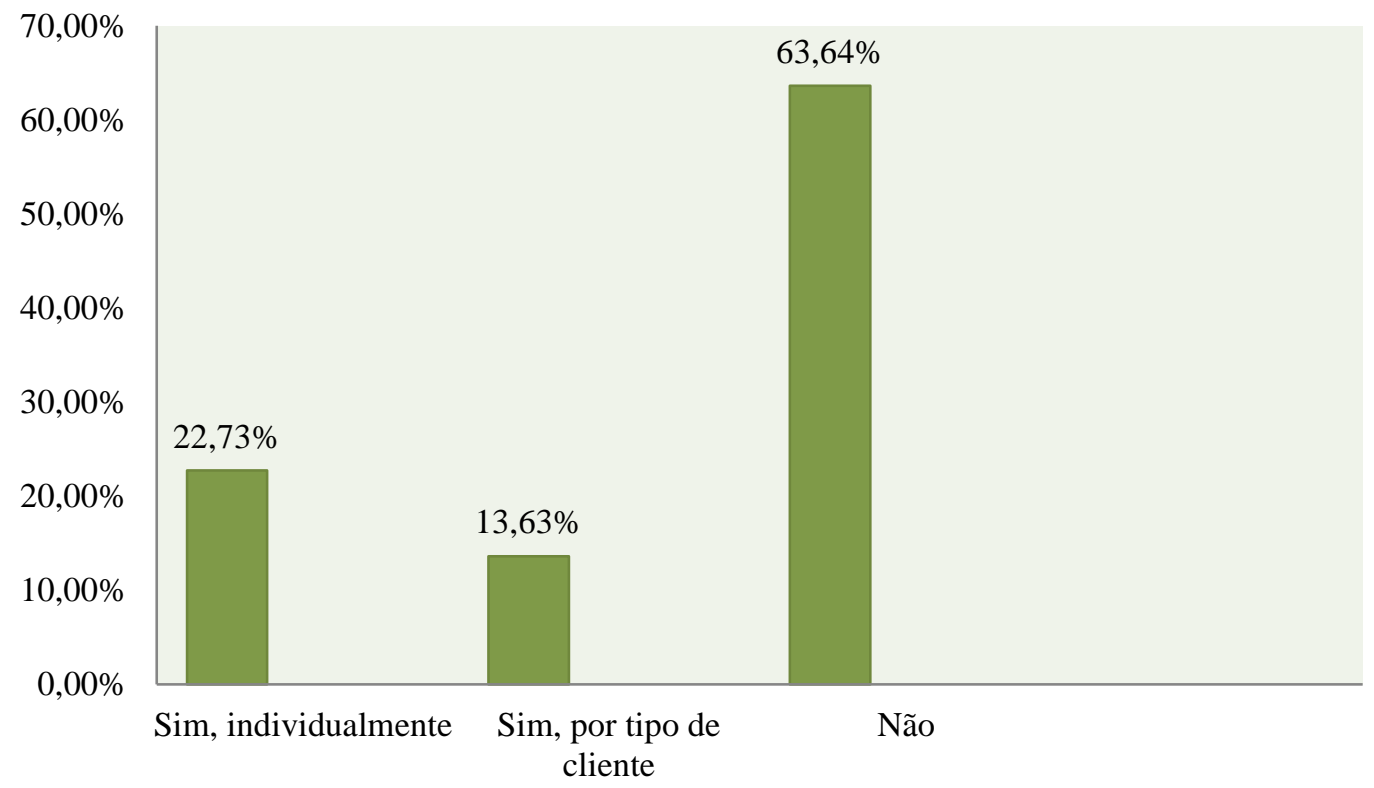

Fonte: dados da pesquisa

Revista Ambiente Contábil - ISSN 2176-9036 - UFRN - Natal-RN. v. 10. n. 2, p. 326 - 341, jul./dez. 2018. 
Em seguida foi perguntado se o hotel realizava a gestão de clientes. Como apresentado na Figura 8, dentre os hotéis componentes da amostra, 59,10\% afirmaram gerir seus clientes.

Figura 8 - Realização da Gestão de Clientes

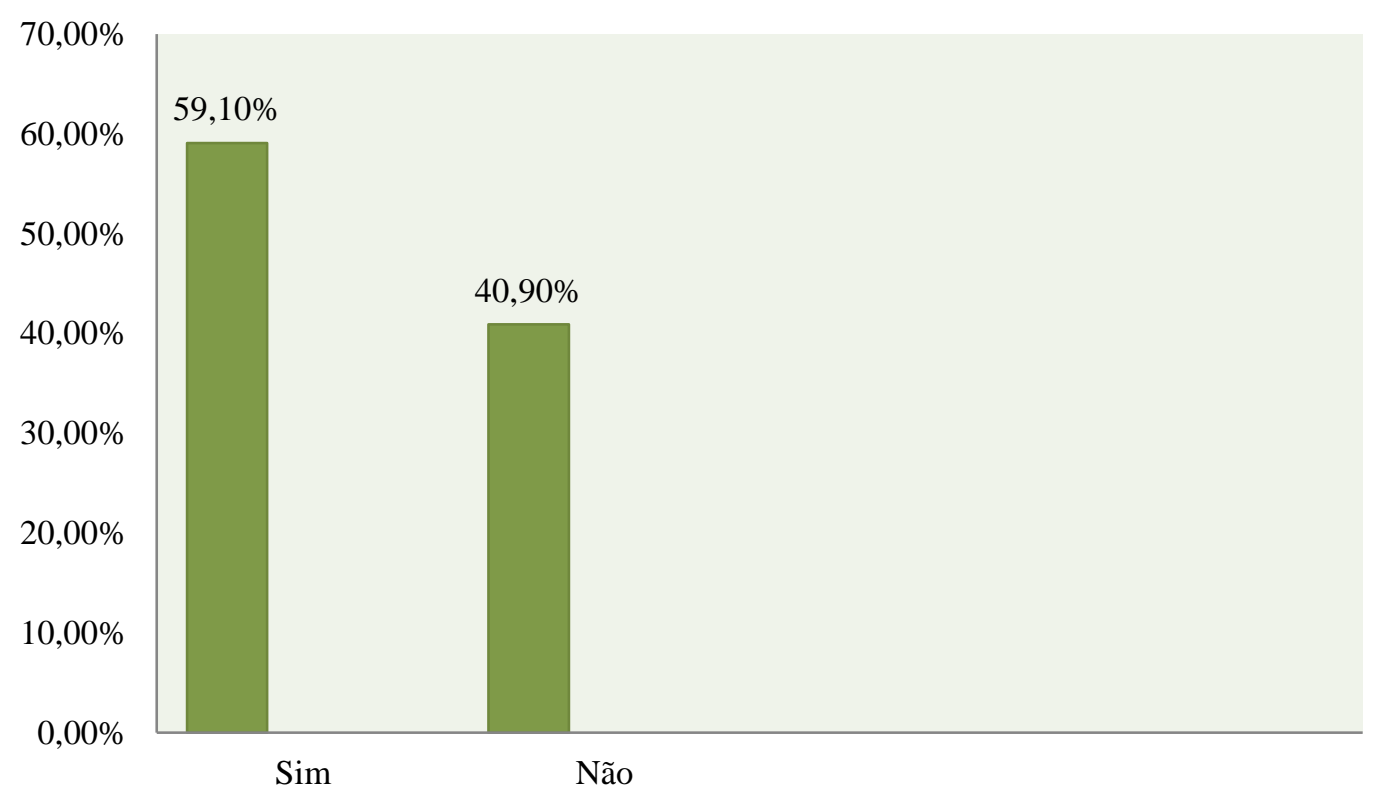

Fonte: dados da pesquisa

Foi proposto àqueles que responderam afirmativamente à questão 8, que informassem quais os conceitos/ferramentas eram utilizados na gestão de clientes. Um hotel respondeu usar um sistema próprio, que não foi especificado. Três hotéis afirmaram usar softwares que auxiliavam no gerenciamento da empresa, foram citados o PMS (Property Management Systems) e o CRM (Customer Relationship Management). Sobre o CRM, ressalta-se de que esse se configura como uma das abordagens teóricas dos estudos relacionados à rentabilidade de clientes, conforme exposto no referencial teórico.

Os demais seguiram a mesma linha das respostas, no entanto retrataram também o uso de redes sociais como: e-mail, instagram e facebook para receber o feedback das estadias, caixas de reclamações e sugestões disponíveis no estabelecimento. Também descreveram buscam também estratégias de marketing para criar essa relação com o cliente, como o desenvolvimento de campanhas e promoções.

Finalmente, foi perguntado de o hotel considerava importante dispor de um sistema de informações capaz de proporcionar a análise da rentabilidade de clientes.

Foi constatado, como mostra a Figura 9, que 68,19\%\% dos hotéis consideram importante dispor de um sistema capaz de proporcionar a análise da rentabilidade de clientes. Embora tenha sido observada uma importância atribuída pela maioria, esse resultado é inferior ao observado por Leitão (2002), que obteve um percentual de $85 \%$ de hotéis que consideravam importante dispor de um sistema com essa capacidade. 


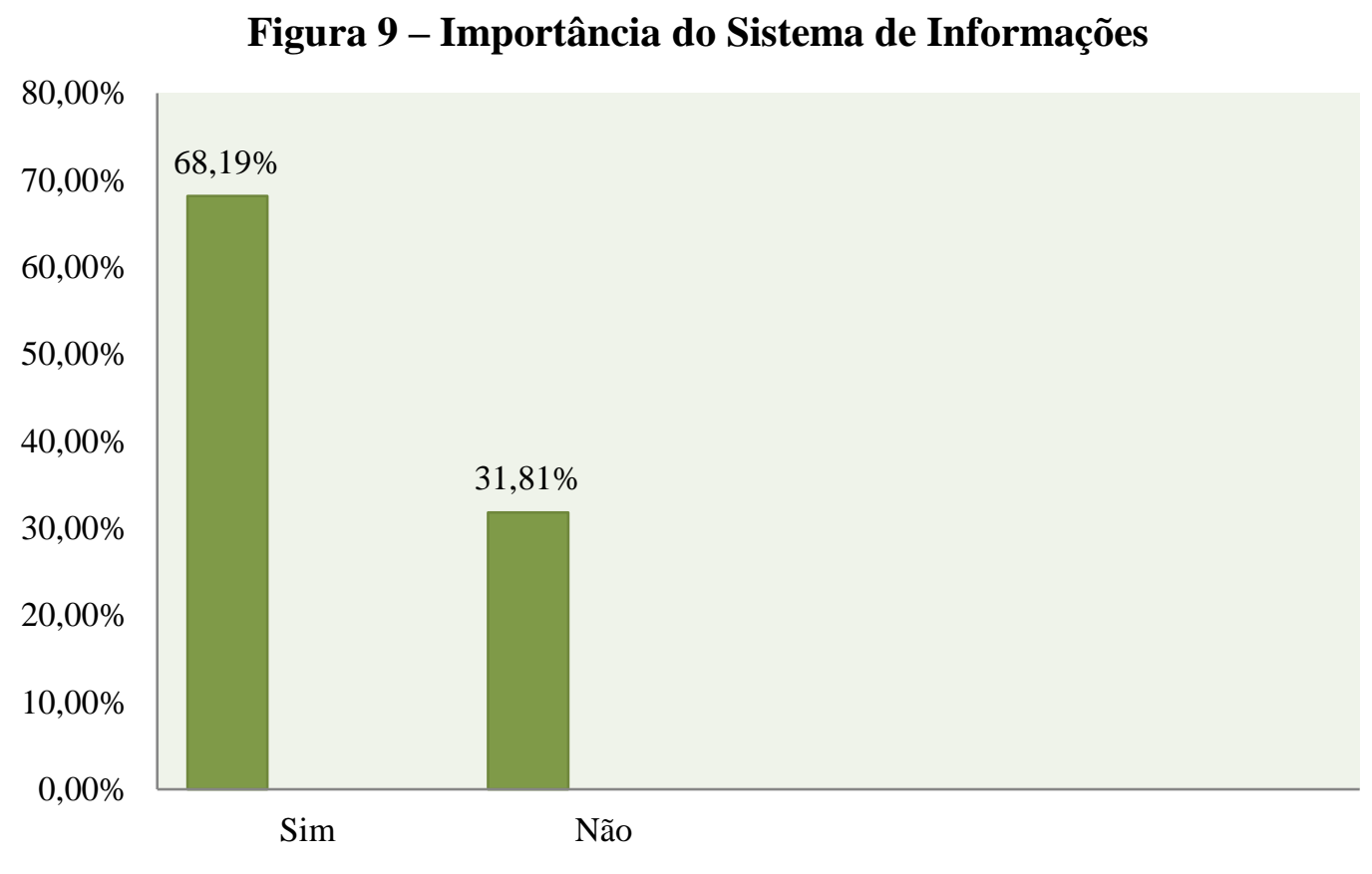

Fonte: dados da pesquisa

Dos hotéis que responderam "não" a essa questão, apenas um se justificou, afirmando que não considerava importante, pois "trabalham por habitação", ou seja, eles levam em consideração o retorno financeiro que obtém a cada UH e não por cliente pessoa individual.

\section{CONSIDERAÇÕES FINAIS}

Num cenário marcado pelo aumento da competitividade, surge a necessidade das empresas aprimorarem suas práticas gerenciais através da introdução de conceitos voltados, dentre outros aspectos, para o aumento da qualidade das decisões. No que diz respeito às decisões envolvendo clientes, destaca-se a prática da análise da rentabilidade de clientes.

Considerando a importância que as empresas da indústria hoteleira têm na economia brasileira, surgiu a questão de como a análise da rentabilidade de clientes. Para responder à questão, realizou-se uma pesquisa nos hotéis de Pernambuco, utilizando-se uma amostra não probabilística formada por 22 hotéis pernambucanos cadastrados na CADASTUR, os quais aceitaram responder o instrumento de pesquisa.

Assim, como resposta ao problema apresentado, observou-se que a maioria dos hotéis, embora considere importante, não realiza a análise da rentabilidade de clientes e que a maioria, embora possua um banco de dados de clientes, não tem as informações sobre a rentabilidade contemplada em seu sistema informacional.

Com o resultado da pesquisa, acredita-se ter contribuído para a o estudo do uso das informações sobre a rentabilidade de clientes na gestão dos hotéis, bem como da utilização da sua análise na gestão dessas entidades, o que pode contribuir para os estudos sobre as práticas na gestão hoteleira.

Acredita-se que a análise da rentabilidade de clientes pode contribuir para a eficácia do processo de gestão nos hotéis, melhorando a qualidade das informações e das decisões relativas a negócios efetuados.

Finalmente, dado o número de hotéis que retornaram os questionários e fato da amostra ser não probabilística, os resultados obtidos não permitem generalizações para todos os hotéis de Pernambuco, o que representa uma limitação do trabalho. Por isso, sugere-se para pesquisas futuras a ampliação do estudo para outros Estados brasileiros, bem como a ampliação da 
amostra. Além disso, sugere-se ainda a pesquisa dos motivos que levam os hotéis a adotar ou não a análise da rentabilidade de clientes, bem como as possíveis dificuldades em implementála.

\section{REFERÊNCIAS}

CHING, H. Y. Gestão Baseada em Custeio por Atividades. 2. ed. São Paulo: Atlas, 1997.

FARRIS, P. W.; BENDLE, N. T.; PFEIFER, P. E.; REIBSTEIN, D. J. Métricas de Marketing: Mais de 50 métricas que todo executivo deve dominar. Porto Alegre: Bookman, 2007.

GUERREIRO, R. Modelo conceitual de sistema de informação de gestão econômica: uma contribuição à teoria da comunicação da contabilidade. 1989. Tese (Doutorado em Controladoria e Contabilidade) - Faculdade de Economia, Administração e Contabilidade, Universidade de São Paulo, São Paulo, 1989.

GUERREIRO. R. A Meta da Empresa: seu alcance sem mistérios. 2ed. São Paulo: Atlas, 1999.

GUERREIRO, R.; MERSCHMANN, E. V. V.; BIO, S.R. Mensuração do custo para servir e análise de rentabilidade de cliente: uma aplicação em indústria de alimento no Brasil. Revista de Administração-eletrônica, v.1, n. 2, 2008.

HASTENTEUFLE, C.; LARENTIS, F. Análise da rentabilidade de clientes através da margem de contribuição: um estudo em uma empresa de médio porte do setor moveleiro na Serra Gaúcha. 2014. Revista Produção e Desenvolvimento, v. 1, n. 1, p. 60-76.

JACKMAN, S. M.; SHANAHAN, Y. Customer Profitability Analysis. New Zeland Journal of Applied Business Research, v. 1, n. 1, 2002.

JACOBS, F.A.; JOHNSTON, W.; KOTCHETOVA, N. Customer Profitability: Prospective vs. Retrospective Approaches in a Busines-to-Business Setting. Industrial Marketing Management, v. 30, n. 4, p. 353-363, 2001.

LEITÃO, C.R.S. Investigação da Rentabilidade de Clientes: um estudo no setor hoteleiro no nordeste. Dissertação (Mestrado em Ciências Contábeis), Universidade de Brasília, Brasília, 2002.

SÁ, A.L. Dicionário de Contabilidade. 8 ed.São Paulo: Atlas, 1990.

MEGLIORINI, E. Custos - Análise e Gestão. 3 ed. São Paulo: Pearson, 2011.

MIA, L.; PATIAR, A. The use of management accounting systems in hotels: an exploratory study. International Journal of Hospitality Management, v. 20, n. 2, p. 111-128, 2001.

MULHERN, F. J. Customer profitability analysis: measurement, concentration, and research directions. Journal of Interactive Marketing, v. 13, n. 1, p. 25-40, 1999. 
PIVA, L. C.; FUMAGALLI, L. A. W.; BAPTISTA, P. de P.; SILVA, W. V. da. Relação entre satisfação, retenção e rentabilidade de clientes no setor de plano de saúde. Revista de Ciências da Administração, v.9, n.19, p. 54-80, 2007.

ROSA, F; Canais de Atendimento Eletrônico e Satisfação, Retenção e Rentabilidade de Clientes em Bancos: um estudo em nível de indivíduo. 2001. Dissertação (Mestrado em Administração), Universidade de Brasília, Brasília. 2001.

RYALS, L.; KNOX, S. Measuring risk adjusted customer lifetime value and its impact on relationship marketing strategies and shareholder value. European Journal of Marketing, v. 39, n. 5, p.456-472, 2005.

SANTANA, A.L.A.; ANDRADE, M.E.M.C. Ensaio sobre rentabilidade de clientes: um enfoque setorial. In: Congresso Brasileiro de custo, 18, 2011, Rio de Janeiro. Anais... Rio de Janeiro, 2011. Disponível em: anaiscbc.emnuvens.com.br.

WYNER, G. O. Customer Profitability. Marketing Management, v. 8, n. 4, p. 8-9, 1999. 